\title{
BMJ Open Association of musculoskeletal pain in other body parts with new-onset shoulder pain: a longitudinal study among survivors of the Great East Japan Earthquake
}

Yoshihiro Hagiwara (D) , ${ }^{1}$ Yutaka Yabe, ${ }^{1}$ Takuya Sekiguchi (D) , ${ }^{1}$ Yumi Sugawara (D) , Masahiro Tsuchiya, ${ }^{3}$ Shinichirou Yoshida, ${ }^{1}$ Takahiro Onoki, ${ }^{1}$ Tadahisa Takahashi, ${ }^{1}$ Jun Iwatsu, ${ }^{1}$ Ichiro Tsuji, ${ }^{2}$ Eiji Itoi ${ }^{1}$

To cite: Hagiwara Y, Yabe Y, Sekiguchi T, et al. Association of musculoskeletal pain in other body parts with new-onset shoulder pain: a longitudinal study among survivors of the Great East Japan Earthquake. BMJ Open 2021;11:e041804. doi:10.1136/ bmjopen-2020-041804

- Prepublication history for this paper is available online. To view these files, please visit the journal online (http://dx.doi. org/10.1136/bmjopen-2020041804).

Received 19 June 2020

Revised 02 November 2020 Accepted 11 November 2020

Check for updates

(C) Author(s) (or their employer(s)) 2021. Re-use permitted under CC BY-NC. No commercial re-use. See rights and permissions. Published by BMJ.

For numbered affiliations see end of article.

Correspondence to Dr Yoshihiro Hagiwara; hagi@med.tohoku.ac.jp

\section{ABSTRACT}

Objective Shoulder pain is a common health problem coexisting with other musculoskeletal pain. However, the effects of pre-existing musculoskeletal pain on the development of shoulder pain are not clear. The present study aimed to elucidate the association between coexisting musculoskeletal pain at other body sites and new-onset shoulder pain among survivors of the Great East Japan Earthquake (GEJE).

Design This is a longitudinal study.

Setting The study was conducted at the severely damaged coastal areas in Ishinomaki and Sendai cities. Participants The survivors who did not have shoulder pain at 3 years after the GEJE were followed up 1 year later $(\mathrm{n}=2131)$.

Interventions Musculoskeletal pain (low back, hand and/ or foot, knee, shoulder and neck pain) was assessed using self-reported questionnaires.

Main outcome measures The outcome of interest was new-onset shoulder pain, which was defined as shoulder pain absent at 3 years but present at 4 years after the disaster. The main predictive factor for newonset shoulder pain was musculoskeletal pain in other body parts at 3 years after the GEJE; this was categorised according to the number of pain sites $(0,1, \geq 2)$. Multiple regression analyses were conducted to calculate the odds ratio (OR) and 95\% confidence interval $(\mathrm{Cl})$ for new-onset shoulder pain due to musculoskeletal pain in other body parts.

Results The incidence of new-onset shoulder pain was $6.7 \%$ (143/2131). Musculoskeletal pain in other body parts was significantly associated with newonset shoulder pain. Using the survivors without other musculoskeletal pain as reference, the adjusted $\mathrm{OR}$ and $95 \% \mathrm{Cl}$ for new-onset shoulder pain were 1.86 (1.18 to 2.94 ) for those with one body part and 3.22 (2.08 to 4.98 ) for those with $\geq 2$ body parts presenting with musculoskeletal pain $(p<0.001)$.

Conclusions Pre-existing musculoskeletal pain in other body parts was significantly associated with new-onset shoulder pain among survivors; this provides useful information for clinical and public health policies.
Strengths and limitations of this study

The strength of this study was its longitudinal design and large sample size, which allowed the performance of stratified analyses for the investigation of the research question.

- As for our study limitations, the questionnaires and informed consent forms were mailed to the participants, with a relatively low response rate for the first time period.

- The reliability and validity of the self-reported questionnaire used to assess musculoskeletal pain in our study were not evaluated.

- While this questionnaire included five pain sites without illustration, it did not include other pain sites such as the hip or elbow that are important for maintaining the kinematic chain.

- The generalisability of the results of our study, which was conducted on disaster survivors, is unclear.

\section{BACKGROUND}

Nine years have passed since the Great East Japan Earthquake (GEJE) and a devastating tsunami hit the northeastern coast of Japan hard on 11 March 2011. Approximately 18400 individuals were confirmed dead or missing, and 3739 died from related events after the GEJE. ${ }^{1}$ Although reconstruction has continued and the number of survivors who have had to flee from their hometowns has decreased in some areas, more than 48000 survivors still remain far from their hometowns. ${ }^{1}$ It is well known that natural disasters are associated with chronic and long-term health problems including psychological disorders, physical inactivity and functional disabilities due to the impact of life-threatening stress and changes in living 
conditions resulting from the devastation of home environments and public health systems. ${ }^{2-4}$

Most pain syndromes after earthquakes or natural disasters are caused by traumatic events in the acute phase. ${ }^{5}$ However, multiple causes have affected chronic pain among survivors in the recovery phase.$^{4-6}$ The prevalence of musculoskeletal pain has been reported to be higher in the recovery phase after the GEJE, and almost half of the survivors experienced musculoskeletal pain at multiple sites. ${ }^{7}$ Furthermore, musculoskeletal pain is associated with new-onset poor physical function, psychological distress and continued residence in temporary prefabricated housing in the recovery phase after the GEJE. ${ }^{7-10}$ Multiple factors influence musculoskeletal pain in GEJE survivors, and an improved understanding of these factors is important to provide better care.

In a cross-sectional study, the three most frequent sites of chronic pain in GEJE survivors after 1.5 years were the knee and surrounding regions, low back and shoulder. ${ }^{6}$ Subjective shoulder pain after the GEJE was significantly associated with sleep disturbances in a prospective cohort study ${ }^{11}$ and with living status, economic hardship and sleep disturbance in a cross-sectional study. ${ }^{12}$ Nevertheless, there have been no reports on the association between subjective pain apart from the shoulder (hereafter referred to as 'other musculoskeletal pain') and newonset subjective shoulder pain. As musculoskeletal pain coexists at multiple sites, we speculated that the increase in musculoskeletal pain in other body parts might be associated with new-onset shoulder pain and lead to a higher prevalence of shoulder pain after natural disasters. The present longitudinal study aimed to examine the association between existing musculoskeletal pain and new-onset shoulder pain during the recovery phase after the GEJE. Clarifying this association may be helpful in preventing and treating shoulder pain after a disaster.

\section{METHODS}

\section{Participants}

A panel study was conducted on GEJE survivors residing in severely damaged coastal areas, including Ogatsu and Oshika areas in Ishinomaki City and Wakabayashi Ward in Sendai City, Miyagi Prefecture, Japan. The main purpose of this study was to better understand the physical, mental and social problems of the survivors in order to improve their social and medical support. The surveys began at 3 months after the GEJE and were administered every 6 months. The first study population included residents registered in the Residential Registry of the Ogatsu and Oshika areas and survivors living in prefabricated housing in the Wakabayashi Ward. Because the number of responders increased until 3 years after the GEJE and remained constant after that period, we adopted the data at 3 and 4 years after the GEJE. From November 2013 to February 2014, 3 years after the GEJE, residents, aged 18 years or older and who were registered in the Residential Registry of

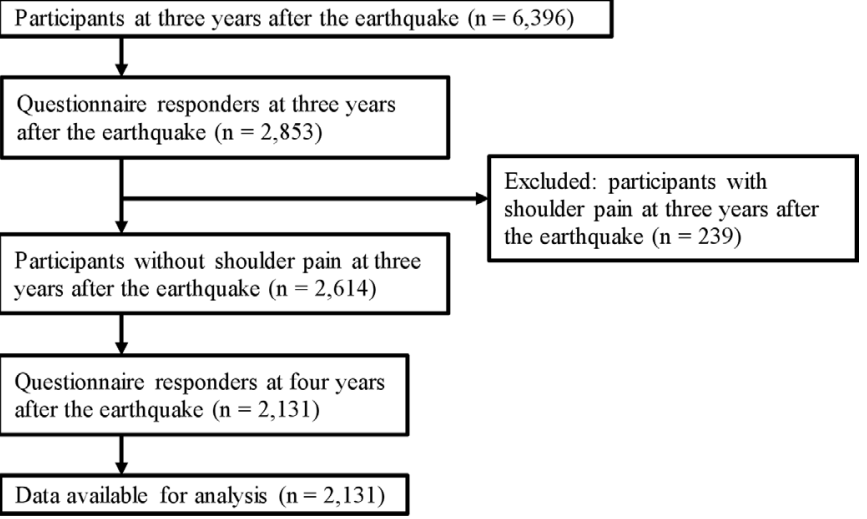

Figure 1 Flowchart of this study.

Ogatsu and Oshika areas, and survivors, who had participated in the previous survey in Wakabayashi Ward, were recruited $(n=6396)$. Self-reported questionnaires and informed consent forms were mailed to these residents, and a $44.6 \%(2853 / 6396)$ response rate was obtained. Of these, participants who already had shoulder pain were excluded $(n=239)$. The remaining participants were followed up from November 2014 to February 2015, 4 years after the GEJE, and an 81.5\% (2131/2614) follow-up rate was obtained for this period. Finally, 2131 participants were included in this study (figure 1).

\section{Musculoskeletal pain}

Musculoskeletal pain was assessed using self-reported questionnaires based on the Comprehensive Survey of Living Conditions without illustration. The questions were as follows: 'Have you had symptoms in the last few days? If yes, please place a mark next to all your symptoms'. The examples of choices were palpitation, dizziness, diarrhoea and musculoskeletal symptoms such as low back, hand and/or foot, knee, shoulder and neck pain. ${ }^{7}$ The outcome of interest was new-onset shoulder pain, which was defined as shoulder pain absent at 3 years (the first period) and present at 4 years after the GEJE (the second period). The main predictor was other musculoskeletal pain during the first period, which included hand and/or foot, knee, low back and neck pain. Other musculoskeletal pain was categorised into three groups according to the number of painful sites $(0,1, \geq 2)$.

\section{Covariates}

The following variables were included in the analysis because they were considered as potential cofounding factors in previous reports ${ }^{13-15}$ : sex, age, body mass index (BMI), living area, smoking habits, drinking habits, comorbid conditions (hypertension, diabetes mellitus, myocardial infarction and cerebral stroke), working status, walking time per day, living status, subjective economic conditions, psychological distress (Kessler Psychological Distress Scale), ${ }^{16}$ sleep disturbance (Athens Insomnia Scale) ${ }^{17}$ and social isolation (Lubben Social Network Scale). ${ }^{14}$ 


\section{Statistical analysis}

Univariate and multivariate logistic regression models were used to calculate odds ratios (ORs) and 95\% confidence intervals (CIs) for new-onset shoulder pain according to the number of other musculoskeletal pain sites during the first period. Variables included in the analysis were sex (male or female), age (continuous variable), BMI (continuous variable), living area (Ogatsu, Oshika or Wakabayashi), smoking habit (nonsmoker, smoker or unknown), drinking habit (non-drinker, $<45.6 \mathrm{~g}$ of alcohol per day, $\geq 45.6 \mathrm{~g}$ of alcohol per day or unknown), comorbid conditions (absence or presence of each comorbid condition), working status (unemployed, employed or unknown), walking time per day ( $<30 \mathrm{~min}$, $30 \mathrm{~min}$ to $<1$ hour, $\geq 1$ hour or unknown), living status (living in the same house as before the GEJE, prefabricated housing, new house, others or unknown), subjective economic condition (normal, a little bit hard, hard, very hard or unknown), Kessler Psychological Distress Scale (continuous variable), Athens Insomnia Scale (continuous variable) and the Lubben Social Network Scale (continuous variable). We further divided the participants into subgroups by sex (male or female), and ORs and 95\% CIs for new-onset shoulder pain were calculated in the same manner. For the stratified analysis, multiplicative interaction between other musculoskeletal pain sites and sex was tested using the Wald test. Additionally, the ORs and 95\% CIs for new-onset shoulder pain according to each body part with musculoskeletal pain except shoulder pain in the first period were calculated. We included the same variables (Model 1) and added each musculoskeletal pain such as hand and/or foot, knee, low back and neck pain as covariates (Model 2). All statistical analyses were performed using SPSS V.24.0. A p value of $<0.05$ was considered statistically significant. Furthermore, we used $\mathrm{p}<0.025$ as the significance level in the subgroup analysis in order to avoid alpha error. ${ }^{18}$

\section{Patient and public involvement}

The patients and public were not involved in the development of the research questions, outcome measures or study design. The patients were also not involved in the recruitment and performance of the study.

\section{RESULTS}

Participants' baseline characteristics are summarised in table 1 .

Among 2131 participants, 1343 (63\%), 423 (19.8\%) and $365(17.1 \%)$ had no, one and two or more other musculoskeletal pain sites during the first period, respectively. Participants who reported having other musculoskeletal pain were more likely to be female; to be living in Ogatsu; and to have high BMI, comorbid conditions (eg, hypertension and cerebral stroke), short walking time, subjective economic hardship, higher Kessler Psychological
Distress Scale score, higher Athens Insomnia Scale score and lower Lubben Social Network Scale score (table 1).

The rate of new-onset shoulder pain was $6.7 \%$ (143/2131). The crude and adjusted ORs and 95\% CIs for new-onset shoulder pain according to the number of other musculoskeletal pain sites are presented in table 2.

Other musculoskeletal pain was significantly associated with new-onset shoulder pain in the crude and adjusted analyses. Using survivors without other musculoskeletal pain as a reference, adjusted ORs and 95\% CIs for newonset shoulder pain were 1.86 (1.18 to 2.94) for one musculoskeletal pain site and 3.22 (2.08 to 4.98 ) for $\geq 2$ sites ( $p$ for trend $<0.001$ ) (table 2 ). The results of the stratified analysis are shown in table 3. Other musculoskeletal pain was significantly associated with new-onset shoulder pain in each group. The association was stronger in older ( $\geq 65$ years) participants than in younger $(<65$ years) participants ( $p$ for trend: $<0.001$ for $\geq 65$ years and 0.003 for $<65$ years); additionally, such an association was stronger in male participants than in female participants ( $p$ for trend: $<0.001$ for male participants and $<0.011$ for female participants). There was no statistically significant multiplicative interaction between musculoskeletal pain, except shoulder pain, and age or sex (table 3).

For each musculoskeletal pain site, hand and/or foot pain, low back pain and neck pain were all associated with new-onset shoulder pain in Model 1, and the association was also significant for low back pain and neck pain in Model 2 (table 4).

\section{DISCUSSION}

The present study revealed that other pre-existing musculoskeletal pain was associated with new-onset shoulder pain among survivors in the recovery phase after the GEJE. Furthermore, the effect was stronger with musculoskeletal pain that occurred at multiple sites.

Previous cross-sectional studies have shown that musculoskeletal pain often occurs at multiple sites, such as the shoulder, elbow, knee and low back. ${ }^{1920}$ Chronic musculoskeletal pain in the Japanese general population occurs at a frequency of $15.4 \%$ and is the highest among those aged 30 to 59 years. ${ }^{21}$ However, pain increased at a frequency of $62 \%$ with a mean Numeric Rating Scale score of 2.74 in GEJE survivors. ${ }^{6}$ Furthermore, the prevalence of musculoskeletal pain increased in the recovery phase after the GEJE, and almost half of the survivors experienced musculoskeletal pain at multiple sites. ${ }^{7}$ Musculoskeletal pain was associated with new-onset poor physical function, psychological distress and continued residence in temporary prefabricated housing in the recovery phase after the GEJE, ${ }^{7-10}$ which disturbs activities of daily living. A better understanding regarding influential factors of pain among survivors is necessary to help them to return to their normal life in a manner similar to that before the GEJE.

The shoulder was the third most frequent pain site after the knee and low back among GEJE survivors ${ }^{6}$; 
Table 1 Baseline characteristics of the participants

\begin{tabular}{|c|c|c|c|c|c|c|}
\hline & \multicolumn{4}{|c|}{ Number of musculoskeletal pain except shoulder pain } & \multirow[b]{3}{*}{$P$ value } \\
\hline & & \multirow{2}{*}{$\begin{array}{l}\mathrm{n}(\%) \\
2131\end{array}$} & \multirow{2}{*}{$\begin{array}{l}0 \\
1343\end{array}$} & \multirow{2}{*}{$\begin{array}{ll}1 \\
423\end{array}$} & \multirow{2}{*}{$\begin{array}{ll}\geq 2 \\
365\end{array}$} & \\
\hline & & & & & & \\
\hline \multirow[t]{2}{*}{ Sex } & Male & $985(46.2)$ & $678(50.5)$ & $170(40.2)$ & $137(37.5)$ & \\
\hline & Female & $1146(53.8)$ & $665(49.5)$ & $253(59.8)$ & $228(62.5)$ & $<0.001$ \\
\hline \multirow[t]{2}{*}{ Age (years) } & $<65$ & $1071(50.3)$ & $686(51.1)$ & $208(49.2)$ & $177(48.5)$ & \\
\hline & $\geq 65$ & $1060(49.7)$ & $657(48.9)$ & $215(50.8)$ & $188(51.5)$ & 0.601 \\
\hline \multirow[t]{3}{*}{$\mathrm{BMI}\left(\mathrm{kg} / \mathrm{m}^{2}\right)^{*}$} & 18.5 to $<25$ & $1234(57.9)$ & $800(59.6)$ & $237(56.0)$ & $197(54.0)$ & \\
\hline & $<18.5$ & $62(2.9)$ & $38(2.8)$ & $19(4.5)$ & $5(1.4)$ & \\
\hline & $\geq 25$ & $763(35.8)$ & $455(33.9)$ & $152(35.9)$ & $156(42.7)$ & 0.007 \\
\hline \multirow[t]{3}{*}{ Living area } & Ogatsu & $923(43.3)$ & $573(42.7)$ & $178(42.1)$ & $172(47.1)$ & \\
\hline & Oshika & $800(37.5)$ & $535(39.8)$ & $156(36.9)$ & 109 (29.9) & \\
\hline & Wakabayashi & $408(19.1)$ & $235(17.5)$ & $89(21.0)$ & $84(23.0)$ & 0.005 \\
\hline \multirow[t]{2}{*}{ Smoking habit* } & Non-smoker & $1595(74.8)$ & $1011(75.3)$ & 304 (71.9) & $280(76.7)$ & \\
\hline & Smoker & $413(19.4)$ & 263 (19.6) & $82(19.4)$ & $68(18.6)$ & 0.06 \\
\hline \multirow[t]{3}{*}{ Drinking habits* } & Non-drinker & $1280(60.1)$ & $794(59.1)$ & $259(61.2)$ & 227 (62.2) & \\
\hline & $<45.6 \mathrm{~g}$ of alcohol/day $\dagger$ & 418 (19.6) & $273(20.3)$ & 76 (18.0) & 69 (18.9) & \\
\hline & $\geq 45.6 \mathrm{~g}$ of alcohol/day $\dagger$ & 225 (10.6) & $148(11.0)$ & $40(9.5)$ & $37(10.1)$ & 0.684 \\
\hline \multirow[t]{4}{*}{ Comorbid conditions } & Hypertension & 808 (37.9) & 477 (35.5) & $158(37.4)$ & $173(47.4)$ & $<0.001$ \\
\hline & Diabetes mellitus & $210(9.9)$ & $125(9.3)$ & $40(9.5)$ & $45(12.3)$ & 0.218 \\
\hline & Myocardial infarction & $129(6.1)$ & $75(5.6)$ & $25(5.9)$ & $29(7.9)$ & 0.243 \\
\hline & Cerebral stroke & 27 (1.3) & $12(0.9)$ & $11(2.6)$ & $4(1.1)$ & 0.022 \\
\hline \multirow[t]{2}{*}{ Working status* } & Unemployed & $1109(52.0)$ & $696(51.8)$ & $232(54.8)$ & $181(49.6)$ & \\
\hline & Employed & $976(45.8)$ & $619(46.1)$ & $179(42.3)$ & $178(48.8)$ & 0.366 \\
\hline \multirow[t]{3}{*}{ Walking time/day* } & $\geq 1$ hour & $616(28.9)$ & $423(31.5)$ & $108(25.5)$ & 85 (23.3) & \\
\hline & $30 \mathrm{~min}$ to $<1$ hour & 772 (36.2) & $503(37.5)$ & 135 (31.9) & $134(36.7)$ & \\
\hline & $<30 \mathrm{~m}$ & 707 (33.2) & $394(29.3)$ & $173(40.9)$ & $140(38.4)$ & $<0.001$ \\
\hline \multirow[t]{4}{*}{ Living status* } & Same house as before the GEJE & $530(29.7)$ & $393(29.3)$ & $134(31.7)$ & $90(24.7)$ & \\
\hline & Prefabricated house & $685(38.4)$ & $530(39.5)$ & $171(40.4)$ & $168(46.0)$ & \\
\hline & New house & $224(12.6)$ & $163(12.1)$ & $45(10.6)$ & $40(11.0)$ & \\
\hline & Others & $331(18.6)$ & $246(18.3)$ & $71(16.8)$ & $66(18.1)$ & 0.318 \\
\hline \multirow[t]{4}{*}{ Economic condition* } & Normal & $940(44.1)$ & $653(48.6)$ & $153(36.2)$ & $134(36.7)$ & \\
\hline & A little hard & $553(26.0)$ & $347(25.8)$ & $107(25.3)$ & $99(27.1)$ & \\
\hline & Hard & $416(19.5)$ & $207(15.4)$ & $120(28.4)$ & $89(24.4)$ & \\
\hline & Very hard & $183(8.6)$ & $98(7.3)$ & $42(9.9)$ & $43(11.8)$ & $<0.001$ \\
\hline \multirow{2}{*}{ Psychological distress ${ }^{\star}$} & Absence & $1786(83.8)$ & $1183(88.1)$ & $326(77.1)$ & $277(75.9)$ & \\
\hline & Presence & 265 (12.4) & $110(8.2)$ & 80 (18.9) & $75(20.5)$ & $<0.001$ \\
\hline \multirow[t]{2}{*}{ Sleep disturbance* } & Absence & $1496(70.2)$ & $1060(78.9)$ & $253(59.8)$ & $183(50.1)$ & \\
\hline & Presence & $622(29.2)$ & $273(20.3)$ & $168(39.7)$ & $181(49.6)$ & $<0.001$ \\
\hline \multirow[t]{2}{*}{ Social isolation* } & Absence & $1521(71.4)$ & 984 (73.3) & $289(68.3)$ & $248(67.9)$ & \\
\hline & Presence & $605(28.4)$ & $354(26.4)$ & $134(31.7)$ & $117(32.1)$ & 0.04 \\
\hline
\end{tabular}

*Because each item has a limited number of respondents, the actual number is not necessarily in accordance with the total. $\dagger 22.8 \mathrm{~g}$ of alcohol amounts to one go or traditional unit of sake $(180 \mathrm{~mL})$, which also approximates to two glasses of wine $(200 \mathrm{~mL})$, or beer $(500 \mathrm{~mL})$ in terms of alcohol content. Categorical values are presented as numbers and percentage (\%).

BMI, body mass index; GEJE, Great East Japan Earthquake. 
Table 2 Influence of musculoskeletal pain except shoulder pain on new-onset shoulder pain

\begin{tabular}{|c|c|c|c|c|c|}
\hline & \multicolumn{5}{|c|}{ Number of musculoskeletal pain except shoulder pain } \\
\hline & Total & 0 & 1 & $\geq 2$ & P for trend \\
\hline Participants & 2131 & 1343 & 423 & 365 & \\
\hline Crude OR $(95 \% \mathrm{Cl})$ & & 1 & $2.20(1.43$ to 3.39$)$ & 3.65 (2.44 to 5.45$)$ & $<0.001$ \\
\hline Adjusted OR (95\% Cl) & & 1 & 1.86 (1.18 to 2.94$)$ & 3.22 (2.08 to 4.98$)$ & $<0.001$ \\
\hline
\end{tabular}

Values are adjusted for sex, age, body mass index, living area, smoking habits, drinking habits, complications, working status, walking time, living status, subjective economic condition, psychological distress, sleep disturbance and social isolation.

$\mathrm{Cl}$, confidence interval; OR, odds ratio.

each of these is a common site of pain and disability in the general population. ${ }^{22}$ Shoulder pain is considered to have multifactorial causes and often presents with other pain symptoms. ${ }^{23}{ }^{24}$ Furthermore, shoulder pain of long duration, at high intensity and with a high level of disability predicts persistent complaints. ${ }^{25}{ }^{26}$ There has been speculation in the literature concerning the association between concurrent pains at different sites. Pain at one site can negatively affect motion or posture and places additional burden on the other parts of the body. ${ }^{27}$ Factors associated with pain at one site can also be related to pain at another site..$^{28}$ In addition, pain at one site can cause central sensitisation, which can result in the development of pain at other sites. ${ }^{29}$ These conditions may explain the association between pre-existing musculoskeletal pain and new-onset shoulder pain among GEJE survivors. To our knowledge, this is the first study to report that the effect of other musculoskeletal pain on new-onset shoulder pain becomes stronger with multisite musculoskeletal pain, which is a so-called dose-response relationship. Most studies on musculoskeletal pain have focused on pain at a single site or on regional distribution; however, it is quite important to pay attention to the other pain sites when following survivors.

The stratified analysis according to age and sex categories showed that the association of other musculoskeletal pain with new-onset shoulder pain was also significant among categories in each group, showing the robustness of the association in this study. The rate of musculoskeletal pain was higher in participants aged $<65$ years than in those aged $\geq 65$ years; however, the association between the other musculoskeletal pain and new-onset shoulder pain was stronger in those aged $\geq 65$ years. Generally, musculoskeletal pain, especially multisite pain, has been reported to be more common among older aged people, ${ }^{20}$ and they are considered more vulnerable to such pain.

Table 3 Stratified analysis for each age and sex group

\section{Number of musculoskeletal pain except shoulder pain}

\begin{tabular}{llllll}
\hline Total & 0 & 1 & $\geq 2$ & $\begin{array}{l}\text { P for } \\
\text { trend }\end{array}$ \\
\cline { 5 - 6 } & 1343 & 423 & 365 & interaction
\end{tabular}

\begin{tabular}{|c|c|c|c|c|c|}
\hline \multicolumn{6}{|l|}{ Age (years) } \\
\hline \multicolumn{6}{|l|}{$<65(n=1071)$} \\
\hline No. of events/subjects & 78/1071 (7.3\%) & $36 / 686(5.2 \%)$ & $18 / 208(8.7 \%)$ & 24/177 (13.6\%) & \\
\hline$\geq 65(n=1060)$ & & & & & 0.13 \\
\hline No. of events/subjects & $65 / 1,060(6.1 \%)$ & 20/657 (3.0\%) & 19/215 (8.8\%) & 26/188 (13.8\%) & \\
\hline \multicolumn{6}{|l|}{ Sex } \\
\hline \multicolumn{6}{|l|}{ Male $(n=985)$} \\
\hline No. of events/subjects & $54 / 985$ (5.5\%) & 23/678 (3.4\%) & $11 / 170(6.5 \%)$ & 20/137 (14.6\%) & \\
\hline Adjusted OR $(95 \% \mathrm{Cl})$ & & 1 & 2.06 (0.93 to 4.58$)$ & 5.33 (2.60 to 10.92$)$ & $<0.001$ \\
\hline Female $(n=1146)$ & & & & & 0.29 \\
\hline
\end{tabular}

Values are adjusted for sex, age, body mass index, living area, smoking habits, drinking habits, complications, working status, walking time, living status, subjective economic condition, psychological distress, sleep disturbance and social isolation.

$\mathrm{Cl}$, confidence interval; OR, odds ratio. 
Table 4 Influence of each musculoskeletal pain on new-onset shoulder pain

\begin{tabular}{|c|c|c|c|c|}
\hline & & Absence & Presence & $P$ value \\
\hline \multirow[t]{3}{*}{ Hand or foot pain } & Participants & 1886 & 245 & \\
\hline & New-onset shoulder pain, n (\%) & $113(6.0)$ & 30 (12.2) & \\
\hline & Model 2 OR $(95 \% \mathrm{Cl})$ & 1 & 1.56 (0.96 to 2.54$)$ & 0.075 \\
\hline \multirow[t]{3}{*}{ Knee pain } & Participants & 1853 & 278 & \\
\hline & Model 1 OR $(95 \% \mathrm{Cl})$ & 1 & 1.55 (0.98 to 2.47) & 0.062 \\
\hline & Model 2 OR (95\% Cl) & 1 & 1.07 (0.65 to 1.75$)$ & 0.799 \\
\hline \multirow[t]{3}{*}{ Low back pain } & Participants & 1708 & 423 & \\
\hline & New-onset shoulder pain, n (\%) & $89(5.2)$ & $54(12.8)$ & \\
\hline & Model 1 OR $(95 \% \mathrm{Cl})$ & 1 & 2.28 (1.56 to 3.33$)$ & $<0.001$ \\
\hline \multirow{3}{*}{ Neck pain } & New-onset shoulder pain, n (\%) & $98(5.5)$ & 45 (12.9) & \\
\hline & Model 1 OR $(95 \% \mathrm{Cl})$ & 1 & 2.06 (1.38 to 3.09$)$ & $<0.001$ \\
\hline & Model 2 OR (95\% Cl) & 1 & 1.64 (1.07 to 2.50$)$ & 0.022 \\
\hline
\end{tabular}

Values are adjusted for sex, age, body mass index, living area, smoking habits, drinking habits, complications, working status, walking time, living status, subjective economic condition, psychological distress, sleep disturbance, and social isolation (Model 1). Additionally, adjusted for hand or foot pain, knee pain, low back pain and neck pain (Model 2).

$\mathrm{Cl}$, confidence interval; OR, odds ratio.

However, the rate of musculoskeletal pain was higher in female participants than in male participants; however, the association of musculoskeletal pain with new-onset shoulder pain was stronger in male participants. Musculoskeletal pain, especially at multiple pain sites, was more common among female participants, ${ }^{19} 20$ and various factors, such as menopause and loss of oestrogen, may affect such pain. ${ }^{30}$ Careful attention is required for survivors with multiple pain sites.

Some authors have reported an association between shoulder and low back pain in cross-sectional studies. ${ }^{31}$ Shoulder pain is more commonly clustered with neck pain and most frequently co-occurs with neck pain. ${ }^{32}$ Non-neutral arm postures and continuously active neckshoulder muscles may be key physical factors associated with pain in the neck and shoulder region. ${ }^{33}$ The trapezius muscle in the upper back and neck region controls various movements of the neck and shoulder and has been implicated as an important muscle in the affected region in individuals with neck and shoulder pain. ${ }^{25}$ To our knowledge, the present study is the first to report that pre-existing low back and neck pain were individually associated with new-onset shoulder pain, even if the effects of the other musculoskeletal pain were considered. Conversely, the association of hand or foot pain and knee pain with new-onset shoulder pain was not significant. Musculoskeletal pain except for shoulder pain may be also associated with the other pain, and the association can affect the results. Furthermore, survivors who had shoulder pain in the first period were excluded from this study since the purpose of this study was to assess the effect of musculoskeletal pain except shoulder pain on new-onset shoulder pain. The survivors who already had both shoulder pain and the other musculoskeletal pain were excluded, which could lower the association.

The strength of this study was its longitudinal design and large sample size, which allowed the performance of stratified analyses for the investigation of the research question. Conversely, this study had several limitations. First, the questionnaires and informed consent forms were mailed to the participants, and the response rate for the first time period was not high. Although there is no information regarding non-responders, it might be possible that responders are healthier than non-responders or that more severely affected persons may pay more attention to their situation. These could have affected the reported rate of musculoskeletal pain and strengthened or weakened the association between other musculoskeletal pain sites and new-onset shoulder pain. Additionally, this study used data that were collected at 3 and 4 years after the GEJE. Other periods may present different response rates, which could also affect the results. Second, musculoskeletal pain was assessed using a self-reported questionnaire based on the Comprehensive Survey of Living Conditions. Although this survey is widely accepted in Japan to assess several symptoms in participants, the reliability and validity of this method were not evaluated in this study. Furthermore, while this questionnaire included five pain sites, it did not include other pain sites such as the hip or elbow that are important for maintaining the kinematic 
chain. Pain at these sites could also affect the onset of shoulder pain and were not assessed in this study. In addition, pain severity and frequency were not assessed, and a pain site illustration was not adopted. Differences in severity and frequency of shoulder pain might depend on a number of other musculoskeletal pain sites, which could not be assessed. Finally, this study was conducted on disaster survivors, and the generalisability of the results is unclear. The findings of this study may be extrapolated to the general population; however, this should be ascertained in future studies.

\section{CONCLUSIONS}

Pre-existing musculoskeletal pain at other sites (especially the low back and neck) was associated with new-onset shoulder pain among survivors in the recovery phase after the GEJE. Further research is needed to clarify whether this association is truly causal and examine mechanisms that could explain why people with musculoskeletal pain at other body sites are at a higher risk of developing shoulder pain, which will provide useful information to clinical and public health policies for the management of shoulder pain.

\section{Author affiliations}

${ }^{1}$ Department of Orthopaedic Surgery, Tohoku University School of Medicine, Sendai, Japan

${ }^{2}$ Division of of Epidemiology, Department of Health Informatics and Public Health, Tohoku University Graduate School of Public Health, Sendai, Japan ${ }^{3}$ Department of Nursing, Faculty of Health Science, Tohoku Fukushi University, Sendai, Japan

Contributors YH, YY and IT contributed to study design. YS, MT, TS, SY, YS and TO were responsible for the data collection and supervised the study. TS and YY performed statistical analysis. YH, YY and El wrote the manuscript. YS, MT, TT, JI and IT aided in analysing the data and drafting the manuscript. All authors have read and approved the manuscript.

Funding This work was supported by the Health Sciences Research Grants (H24, 25-Kenki-Shintei-002; Fukkou) from the Ministry of Health, Labor and Welfare of Japan. The funding source had no role in the study design; in the collection, analysis and interpretation of data; and in writing the manuscript.

Competing interests None declared.

Patient consent for publication Not required.

Ethics approval The study protocol was reviewed and approved by the Ethics Committee of Tohoku University Graduate School of Medicine (approval number: 201192) and was performed in accordance with the ethical standards as laid down in the 1964 Declaration of Helsinki and its later amendments or comparable ethical standards. Written informed consent was obtained from all participants.

Provenance and peer review Not commissioned; externally peer reviewed.

Data availability statement Data are available upon reasonable request. All data generated or analysed during this study are included in this published article.

Open access This is an open access article distributed in accordance with the Creative Commons Attribution Non Commercial (CC BY-NC 4.0) license, which permits others to distribute, remix, adapt, build upon this work non-commercially, and license their derivative works on different terms, provided the original work is properly cited, appropriate credit is given, any changes made indicated, and the use is non-commercial. See: http://creativecommons.org/licenses/by-nc/4.0/.

\section{ORCID iDs}

Yoshihiro Hagiwara http://orcid.org/0000-0002-2992-2178

Takuya Sekiguchi http://orcid.org/0000-0003-4642-854X

Yumi Sugawara http://orcid.org/0000-0002-0197-6772
REFERENCES

1 Reconstruction. Recovery and reconstruction from the great East Japan earthquake: reconstruction agency, 2021. Available: http:// www.reconstruction.go.jp/english/topics/Progress_to_date/index. html

2 Kako M, Arbon P, Mitani S. Disaster health after the 2011 great East Japan earthquake. Prehosp Disaster Med 2014;29:54-9.

3 Murakami H, Yoshimura E, Ishikawa-Takata K, et al. The longitudinal change in physical activity among great East Japan earthquake victims living in temporary housing. Nihon Koshu Eisei Zasshi 2014;61:86-92.

4 Tomata Y, Suzuki Y, Kawado M, et al. Long-term impact of the 2011 great East Japan earthquake and tsunami on functional disability among older people: a 3-year longitudinal comparison of disability prevalence among Japanese municipalities. Soc Sci Med 2015;147:296-9.

5 Angeletti C, Guetti C, Papola R, et al. Pain after earthquake. Scand J Trauma Resusc Emerg Med 2012;20:43.

6 Yabuki S, Ouchi K, Kikuchi S-ichi, et al. Pain, quality of life and activity in aged evacuees living in temporary housing after the great East Japan earthquake of 11 March 2011: a cross-sectional study in Minamisoma City, Fukushima Prefecture. BMC Musculoskelet Disord 2015;16:246.

7 Yabe Y, Hagiwara Y, Sekiguchi T, et al. Musculoskeletal pain is associated with new-onset psychological distress in survivors of the great East Japan earthquake. Disaster Med Public Health Prep 2019;13:295-300.

8 Sogi Y, Yabe Y, Hagiwara Y, et al. Association between continued residence in temporary prefabricated housing and musculoskeletal pain in survivors of the great East Japan earthquake: a longitudinal study. BMJ Open 2019;9:e030761.

9 Yabe Y, Hagiwara Y, Sekiguchi T, et al. Musculoskeletal pain and new-onset poor physical function in elderly survivors of a natural disaster: a longitudinal study after the great East Japan earthquake. BMC Geriatr 2019;19:274.

10 Yabe Y, Hagiwara Y, Sekiguchi T, et al. Higher incidence of sleep disturbance among survivors with musculoskeletal pain after the great East Japan earthquake: a prospective study. Tohoku J Exp Med 2018;244:25-32.

11 Hagiwara Y, Sekiguchi T, Sugawara Y, et al. Association between sleep disturbance and new-onset subjective shoulder pain in survivors of the great East Japan earthquake: a prospective cohort study in Miyagi Prefecture. Tohoku J Exp Med 2017;242:193-201.

12 Hagiwara Y, Sekiguchi T, Yabe Y, et al. Living status, economic hardship and sleep disturbance were associated with subjective shoulder pain in survivors of the great East Japan earthquake: a cross sectional study. J Orthop Sci 2017;22:442-6.

13 Hagiwara Y, Yabe Y, Sugawara Y, et al. Influence of living environments and working status on low back pain for survivors of the great East Japan earthquake. J Orthop Sci 2016;21:138-42.

14 Sone T, Nakaya N, Sugawara Y, et al. Longitudinal association between time-varying social isolation and psychological distress after the great East Japan earthquake. Soc Sci Med 2016;152:96-101.

15 Yabe Y, Hagiwara Y, Sekiguchi T, et al. Influence of living environment and subjective economic hardship on new-onset of low back pain for survivors of the great East Japan earthquake. J Orthop Sci 2017;22:43-9.

16 Suzuki Y, Fukasawa M, Obara A, et al. Mental health distress and related factors among prefectural public servants seven months after the great East Japan earthquake. J Epidemiol 2014;24:287-94.

17 Soldatos CR, Dikeos DG, Paparrigopoulos TJ. Athens insomnia scale: validation of an instrument based on ICD-10 criteria. $J$ Psychosom Res 2000;48:555-60.

18 Wang R, Lagakos SW, Ware JH, et al. Statistics in medicine-reporting of subgroup analyses in clinical trials. $N$ Engl J Med 2007;357:2189-94.

19 Coggon D, Ntani G, Palmer KT, et al. Patterns of multisite pain and associations with risk factors. Pain 2013;154:1769-77.

20 Kamaleri Y, Natvig B, Ihlebaek CM, et al. Change in the number of musculoskeletal pain sites: a 14-year prospective study. Pain 2009;141:25-30.

21 Nakamura M, Nishiwaki Y, Ushida T, et al. Prevalence and characteristics of chronic musculoskeletal pain in Japan. $J$ Orthop Sci 2011;16:424-32.

22 Luime JJ, Koes BW, Hendriksen IJM, et al. Prevalence and incidence of shoulder pain in the general population; a systematic review. Scand J Rheumatol 2004;33:73-81.

23 Huygen F, Patijn J, Rohof O, et al. 9. Painful shoulder complaints. Pain Pract 2010;10:318-26.

24 Leijon O, Wahlström J, Mulder M. Prevalence of self-reported neckshoulder-arm pain and concurrent low back pain or psychological 
distress: time-trends in a general population, 1990-2006. Spine 2009;34:1863-8.

25 Kuijpers T, van der Windt DAWM, van der Heijden GJMG, et al. Systematic review of prognostic cohort studies on shoulder disorders. Pain 2004;109:420-31.

26 Macfarlane GJ, Hunt IM, Silman AJ. Predictors of chronic shoulder pain: a population based prospective study. J Rheumatol 1998;25:1612-5.

27 Ito H, Tominari S, Tabara Y, et al. Low back pain precedes the development of new knee pain in the elderly population; a novel predictive score from a longitudinal cohort study. Arthritis Res Ther 2019;21:98.

28 Croft P, Dunn KM, Von Korff M. Chronic pain syndromes: you can't have one without another. Pain 2007;131:237-8.

29 Fernández-de-las-Peñas $\mathrm{C}$, Hernández-Barrera V, Alonso-Blanco $\mathrm{C}$, et al. Prevalence of neck and low back pain in community- dwelling adults in Spain: a population-based national study. Spine 2011;36:E213-9.

30 Pieretti S, Di Giannuario A, Di Giovannandrea R, et al. Gender differences in pain and its relief. Ann Ist Super Sanita 2016;52:184-9.

31 Suri P, Morgenroth DC, Kwoh CK, et al. Low back pain and other musculoskeletal pain comorbidities in individuals with symptomatic osteoarthritis of the knee: data from the osteoarthritis initiative. Arthritis Care Res 2010;62:1715-23.

32 Engebretsen KB, Grotle M, Natvig B. Patterns of shoulder pain during a 14-year follow-up: results from a longitudinal population study in Norway. Shoulder Elbow 2015;7:49-59.

33 Kelson DM, Mathiassen SE, Srinivasan D. Trapezius muscle activity variation during computer work performed by individuals with and without neck-shoulder pain. Appl Ergon 2019;81:102908. 